\title{
Reproductive Aspects of Freshwater Stingrays (Chondrichthyes: Potamotrygonidae) in the Brazilian Amazon Basin
}

\author{
Patricia Charvet-Almeida ${ }^{1}$ \\ Laboratório de Ictiologia, Departamento de Sistemática, Centro de Ciências Exatas e da Natureza \\ Universidade Federal da Paraíba (UFPB), Cidade Universitária - João Pessoa - PB 58059-900, Brazil \\ Maria Lúcia Góes de Araújo \\ Laboratório de Citologia (DM - ICB), Universidade do Amazonas (UA), Av. General Rodrigo Otávio Jordão, \\ 3000 - Coroado - Manaus - AM 69000-077, Brazil \\ and \\ Mauricio Pinto de Almeida \\ Laboratório de Ictiologia, Departamento de Zoologia, Museu Paraense Emílio Goeldi (MPEG), Av. Perimetral, \\ 1901 - Terra Firme - Belém - PA 66077-530, Brazil
}

\begin{abstract}
Charvet-Almeida, P., M. L. G. DE Araújo, and M. P. De Almeida. 2005. Reproductive Aspects of Freshwater Stingrays (Chondrichthyes: Patamotrygonidae) in the Brazilian Amazon Basin. J. Northw. Atl. Fish. Sci., 35: 165-171. doi:10.2960/J.v35.m502
\end{abstract}

\begin{abstract}
Freshwater stingrays (Potamotrygonidae) are the only elasmobranchs completely adapted for living in freshwater and all species studied so far presented a reproductive mode described as matrotrophic viviparity with development of trophonemata. Several specimens were collected, dissected and had their reproductive parameters studied. The following species are being studied: Potamotrygon motoro, P. orbignyi, P. schroederi, P. scobina, Potamotrygon sp., Paratrygon aiereba and Plesiotrygon iwamae. The reproductive cycle in the potamotrygonid species observed is directly related to the hydrologic cycle. All species studied have defined reproductive periods with the following sequence of events: gonadal maturation, copulation, pregnancy, birth and resting. Each species analyzed presented a different reproductive periodicity. Gonadal maturation lasts for an average of about 3 months. Copulation does not happen during the same period of the year for all species and it takes place during the rainy or dry season. The lowest average uterine fecundity observed corresponded to 1 and the highest average value was 8 . The gestation period varied and lasted between 3 to 9 months. Birth season also presented variation and may last from 3 to 4 months. A resting interval was observed in the reproductive cycle of most species. It is expected that the observation of reproductive aspects of freshwater stingrays contributes to the understanding of population dynamics of these species.
\end{abstract}

Key words: Amazon Basin, Brazil, freshwater stingrays, reproduction

\section{Introduction}

Freshwater stingrays (Potamotrygonidae) are the only group among elasmobranchs that is completely adapted for living exclusively in freshwater environments (Compagno and Cook, 1995) and are widely distributed in several river basins of the Neotropical region (Rosa, 1985).

All species of freshwater stingrays studied so far presented a reproductive mode described as matrotrophic viviparity with development of trophonemata (Wourms,
1977, 1981; Wourms et al. 1988). Nevertheless, reproductive aspects of freshwater stingrays have been poorly studied and limited knowledge related to the reproductive characteristics of this group is available. More complete studies started to be performed in the 1980 s and in the 1990s only a few detailed studies were carried out concerning the reproductive biology of these elasmobranchs.

Historically Castex (1963 a) mentioned the reports of José Sánchez Labrador, a Jesuit priest, and of Joseph

\footnotetext{
${ }^{1}$ Laboratório de Ictiologia, Departamento de Zoologia, Museu Paraense Emílio Goeldi (MPEG), Av. Perimetral, 1901 - Terra Firme

- Belém - PA 66077-530, Brazil (email address: pchalm@nautilus.com.br)
} 
Gumibia who in the Eighteenth Century noted that freshwater stingrays were viviparous. Castex (1963 a, b) himself and Castex and Maciel (1965) also made some general observations on the reproduction of these rays in Argentina. Achenbach and Achenbach (1976) were the first authors to observe maternal care in this group and included relevant details in the observations of the reproductive aspects of Potamotrygon motoro and of P. brachyura in the mid Paraná River. Thorson et al. (1983) considered these stingrays aplacentally viviparous in a more complex study that included Potamotrygon constellata and captive breeding observations of P. motoro. Taniuchi and Ishihara (1990) compared anatomically the claspers of some freshwater stingrays (Dasyatidae and Potamotrygonidae). Teshima and Takeshita (1992) examined more closely the reproductive biology of Potamotrygon magdalenae in the Magdalena River system (Colombia) and included histological observations. Lasso et al. (1996) observed the biology of the freshwater stingrays Paratrygon aiereba and Potamotrygon orbignyi and indicated interesting reproductive parameters for these species in the Venezuelan llanos region. Araújo (1998) carried out a detailed study on the reproduction of Potamotrygon sp. C (an undescribed species called "cururu") in the Negro River and included histological aspects. Charvet-Almeida (2001) observed the biology of Plesiotrygon iwamae in the Amazon Mouth region (Marajó Bay) and added data concerning reproductive characteristics of this species.

As may be observed in the paragraph above, the information available up to date is very limited for the species from the Brazilian Amazon Basin. The present study was developed to help fulfill this lack of reproductive biology data from part of the Amazon Basin. This part of the Neotropical region encloses approximately 16 of the 20 valid species of potamotrygonids (Rosa, 1985). Due to this great species diversity and to the size of this region, not all of them have been analyzed so far and data collecting/analysis is still under way. The following species have been studied until now: Plesiotrygon iwamae, Paratrygon aiereba, Potamotrygon motoro, P. orbignyi, P. schroederi, P. scobina and Potamotrygon sp. C. Since reproductive biology studies also demand long-term observation, some results indicated below are still being analyzed and from a conservative point of view should be considered as preliminary results.

The observation of reproductive aspects of freshwater stingrays is essential to provide important data to contribute to the understanding of population dynamics of these rays.

\section{Materials and Methods}

The species included in the present study were captured in two main fishing areas located in the Brazilian Amazon Basin. Data related to the species Potamotrygon motoro, P. schroederi, Potamotrygon sp. $\mathrm{C}$ and Paratrygon aiereba was obtained from the State of Amazonas (Negro River Basin). Information about P. scobina and Plesiotrygon iwamae was collected in the State of Pará (Marajó Bay) and data concerning $P$. orbignyi was originated from both regions.

All specimens were captured with the assistance of local fishermen and involved the use of several fishing methods (seines, long lines, beach trawl nets, etc). Immediately after capture specimens were sacrificed and dissected in order to have their reproductive organs observed. Observations were carried out using both fresh and fixed $(10 \%$ formaldehyde solution buffered with borax) material.

The terminology used in the analyses was adapted from Dodd (1983) and observations were made according to Wourms et al. (1988), Thorson et al. (1983), Peres and Vooren (1991), Araújo (1998) and Charvet-Almeida (2001).

The following detailed macroscopic observations were performed on females organs: ovaries weight, length and aspect; number, diameter and weight of ovarian follicles; oviducts length and width; width, length, color and shape of the egg shell gland; uterine width, length and content; average size of uterine vili; number, stage of development, size and weight of embryos. Ovarian and uterine fecundity parameters were adapted from Peres and Vooren (1991).

The following macroscopic details were recorded on male reproductive organs: testis size, weight and length; epididymides length and width; Leydig gland width; seminal vesicle width, length and number of sections; clasper length and level of calcification; \% of clasper length in relation to disc width and presence or absence of seminal fluid. Slide preparations were also used to check the presence of well-developed and active spermatozoids in the seminal fluid.

Female and male specimens were considered juveniles, or adults, according to the criteria established by Pratt (1988) and Pratt and Otake (1990). 
An overall evaluation of the reproductive organs development stage was done for each specimen analyzed. In some cases, microscopic analyses were required to confirm macroscopic observations.

\section{Results}

The results obtained refer to observations of freshwater stingray reproductive biology in natural habitat conditions. Rays kept in captivity might present different characteristics. An overview of the macro and micro observations provided the results presented in the tables shown. Some results are considered preliminary and the need of further confirmation is indicated by a question mark (?). Other long-term analyses are currently under way and such observations were indicated as "In study".

The species Plesiotrygon iwamae, Paratrygon aiereba, Potamotrygon motoro, P. orbignyi, P. schroederi, Potamotrygon sp. C certainly have their reproductive cycles closely related to the hydrologic cycle of the river basins that they inhabit. For these species the hydrologic cycle triggers the beginning or directly influences all reproductive cycle stages of these potamotrygonid rays. The reproduction of Potamotrygon scobina is probably also related to the hydrologic cycle but data to confirm this is currently under analysis.

The species studied seem to have well defined reproductive periods and a sequence of events related to their reproductive cycles was observed. Gonadal maturation is the first of all steps and takes from 2 up to 4 months to be completed, according to each species
(Table 1). Copulation period also varies among species and occurs during dry or rainy season that respectively correspond to low waters or flood season in the Amazonian river basins (Table 1). Pregnancy periods lasted from 3 to up to 9 months and length variations occurred among different species (Table 2). Birth season predominantly takes place during the rainy season and its length presented little variation lasting 3 or 4 months (Table 2). All species presented a reproductive resting period in their cycles.

The ovarian fecundity varied among species and only the left ovary seemed to be functional. The lowest value observed was of one and the highest was of up to eleven oocytes (ripe ova) per ovary (Table 3 ). Both uteri were functional in all species analyzed. Uteri presented an average number of embryos that varied from 1 to 8 , however, in some specimens up to 16 embryos were registered (Table 3). Potamotrygonid pregnant females easily abort when they are captured and this certainly represents a challenge to correctly estimate the uterine fecundity. The uterine fecundity seemed to be slightly lower than the ovarian fecundity.

Males mature at a smaller disc width size than females and these sizes varied among the different species analyzed (Table 3).

The age of sexual maturity has only been estimated for two species so far. The estimated age of maturity for Paratrygon aiereba was of approximately 35 years. On the other hand, the small "cururu" freshwater stingray (Potamotrygon sp. C) seemed to reach sexual maturity much earlier at an estimated age of only 2 years.

TABLE 1. Observations of gonadal maturation and copulation period (see text for terms used).

\begin{tabular}{lcc}
\hline \hline & \multicolumn{2}{c}{ Reproductive Aspects } \\
\cline { 2 - 3 } Species & $\begin{array}{c}\text { Gonadal maturation } \\
\text { period (months) }\end{array}$ & $\begin{array}{c}\text { Copulation in specific period? } \\
\text { (dry or rainy season) }\end{array}$ \\
\hline Plesiotrygon iwamae $(n=51)$ & $2-3$ & Yes, rainy \\
Paratrygon aiereba $(n=101)$ & In study & In study \\
Potamotrygon motoro $(n=110)$ & $3-4$ & Yes, dry \\
P. orbignyi $(n=449)$ & $3-4$ & Yes, rainy \\
P. schroederi $(n=43)$ & $3-4$ & Yes, rainy \\
P. scobina $(n=343)$ & In study & In study \\
Potamotrygon $\mathrm{sp} . \mathrm{C}(n=153)$ & 2 & Yes, rainy \\
\hline
\end{tabular}


TABLE 2. Pregnancy and birth data (see text for terms used).

\begin{tabular}{lccc}
\hline \hline & Pregnancy & & Birth \\
\cline { 2 - 4 } Species & $\begin{array}{c}\text { Gestation period } \\
\text { (months) }\end{array}$ & $\begin{array}{c}\text { Period } \\
\text { (dry or rainy season) }\end{array}$ & $\begin{array}{c}\text { Season length } \\
\text { (months) }\end{array}$ \\
\cline { 3 - 4 } Plesiotrygon iwamae $(n=15)$ & $8(?)$ & Transition dry to rainy & 3 \\
Paratrygon aiereba $(n=2)$ & $9(?)$ & Rainy & 4 \\
Potamotrygon motoro $(n=18)$ & 6 & Rainy & 4 \\
Potamotrygon orbignyi $(n=14)$ & $6(?)$ & Rainy & 4 \\
Potamotrygon schroederi $(n=5)$ & $6(?)$ & Rainy & 4 \\
Potamotrygon scobina $(n=31)$ & In study & In study & In study \\
Potamotrygon sp. C $(n=35)$ & 3 & Dry & 3 \\
\hline
\end{tabular}

TABLE 3. Ovarian and uterine fecundity and sexual maturity disc width of the studied species (see text for terms used).

\begin{tabular}{llcl}
\hline \hline & \multicolumn{2}{c}{ Fecundity } & Sexual maturity \\
\cline { 2 - 3 } Species & Ovarian & Uterine (average) & $\begin{array}{c}\text { Disc width } \\
\text { males/females }(\mathrm{mm})\end{array}$ \\
\hline Plesiotrygon iwamae & $1-5(n=22)$ & $1-4(2)(n=15)$ & $400(n=30) / 500(n=22)$ \\
Paratrygon aiereba & $3-5(n=45)$ & $2(2)(n=2)$ & $600(n=56) / 720(n=45)$ \\
Potamotrygon motoro & $6-11(n=50)$ & $4-11(7)(n=18)$ & $390(n=60) / 440(n=50)$ \\
P. orbignyi & $3-7(n=162)$ & $1-5(2)(n=14)$ & $390(n=237) / 440(n=212)$ \\
P. schroederi & $3-7(n=20)$ & $1-3(2)(n=5)$ & $420(n=23) / 440(n=20)$ \\
P. scobina & $1-13(n=107)$ & $1-16(6)(?)(n=31)$ & $350(?)(n=130) / 400(?)(n=107)$ \\
Potamotrygon sp. C & $9(n=70)$ & $1-5(2)(n=35)$ & $160(n=83) / 170(n=70)$ \\
\hline
\end{tabular}

\section{Discussion}

Neotropical freshwater stingrays have been considered completely adapted to freshwater environments because they have the ability to osmoregulate and reproduce in such habitats (Thorson et al., 1983). Most Amazonian river basins present a well-defined hydrologic cycle (Goulding, $1980 ; 1997)$ and by inhabiting these water systems it is very probable that the freshwater stingrays had to adapt their life cycles to these cyclic conditions. Other authors have suggested that the potamotrygonid reproductive cycle presents clearly defined periods for each of its basic steps: gonadal maturation, copulation, pregnancy and birth (Castex, 1963 a, b; Castex and Maciel, 1965; Achenbach and Achenbach, 1976). Most of these authors associated these defined periods to months or seasons of the year but made little or no reference to changes in the hydrologic cycle of the river basins where their work was developed. Achenbach and Achenbach (1976) suggested that $P$. hystrix moved or migrated in the Paraná River by mentioning that in determined places and periods of the year the freshwater stingrays could be fished more easily than in others. Lasso et al. (1976) and Araújo (1998) evidenced that there was a close and clear relationship between the reproduction of the species studied and the regional hydrologic cycles. Charvet-Almeida (2001) indicated that the reproductive cycle of Plesiotrygon iwamae probably was affected by slight salinity changes that occurred in the study area (Marajó Bay). Curiously Teshima and Takeshita (1992) did not find this for P. magdalenae in the Magdalena River. In captivity Thorson et al. (1983) noted that reproductive activity seemed to be triggered by water temperature changes and Lasso et al. (1996) pointed out that the beginning of the rainy season and high water are followed by physico-chemical water changes. It is very probable that changes in water characteristics associated with changes in the hydrologic cycle actually trigger the beginning and subsequent steps of most species' reproductive cycles in the Amazon Basin region.

Little is known for sure about the gestation period of potamotrygonids. Winemiller (1989) estimated that P. orbignyi had a pregnancy period of 11 months. Araújo (1998) indicated a much shorter period for Potamotrygon sp. C of 3 months. Charvet-Almeida (2001) indicated that probably Plesiotrygon iwamae had a gestation period of up 
to 8 months. Other studies involving marine rays indicated that Urolophus halleri (Babel, 1967) and Rhinobatos horkelli (Lessa, 1982) had a cycle with a period of 7 months of reproduction alternated by a period of 5 months of reproductive rest.

The great majority of all potamotrygonids studied until now seem to have only a left functional ovary. This has been observed for Potamotrygon motoro (Castex, 1963 b; Achenbach and Achenbach, 1976; Thorson et al. 1983; Pratt, 1988), P. brachyura (Castex and Maciel, 1965), P. constellata (Thorson et al. 1983), P. orbignyi (Lasso et al. 1996), Potamotrygon sp. C (Araújo, 1998) and Plesiotrygon iwamae (Charvet-Almeida, 2001). The only exception was indicated by Teshima and Takeshita (1992) when they mentioned that both ovaries of P. magdalenae were functional. Ovary asymmetry is found in other elasmobranch species and is considered a common characteristic among stingrays (Lovejoy, 1996).

All studies involving freshwater stingrays indicated that both uteri are functional and the differences observed in terms of uteri content involved only discrepancies related to the number of embryos found.

The number of embryos varies among potamotrygonid species but cannot be considered high when compared to other elasmobranchs in general. The results obtained seem to agree with most information available from other regions. Plesiotrygon iwamae (Charvet-Almeida, 2001) presented the same number of embryos as indicated in the present study. Thorson et al. (1983) indicated an average of 6-7 embryos for P. motoro, while Achenbach and Achenbach (1976) observed between 9-15 embryos for this same species. Winemiller and Taphorn (1989) observed the presence of 2 embryos for P. orbignyi, while Lasso et al. (1996) registered a single embryo for this same species. Araújo (1998) observed the same variation of 1-5 embryos for Potamotrygon sp. C as the present study. Other species not considered in the present study presented similar number of embryos: between 4-11 for P. constellata (Thorson et al., 1983) and 1 embryo per uteri for $P$. magdalenae (Teshima and Takeshita, 1992). Potamotrygon scobina was the only species that presented a higher maximum number of embryos and a single similar register of this number of embryos was done by Achenbach and Achenbach (1976) for P. brachyura. For both species that Achenbach and Achenbach (1976) studied (P. motoro and P. brachyura) a high number of embryos was noted and this possibly could be related to specific characteristics of the mid Paraná River region where they developed their study.

The common occurrence of abortions among pregnant females was also indicated by Schomburgk (1843), Achenbach and Achenbach (1976) and CharvetAlmeida (2001). Abortions are very frequent and seem to occur when the pregnant females are exposed to stressful conditions. The embryos hardly ever survive in such circumstances despite their development stage.

When comparing ovarian and uterine fecundity a slight reduction in uterine fecundity has been observed previously for Potamotrygon sp. C ("cururu" freshwater stingray) (Araújo, 1998) and for Plesiotrygon iwamae (Charvet-Almeida, 2001). Differences between ovarian and uterine fecundity were observed but were not very high among individuals of the same species. Apparently reproduction involves a high-energy demand and once an oocyte is formed possibly great effort is directed to develop it to a successful embryo.

Males tend to present a smaller disc width size than females and this was observed in all potamotrygonid species analyzed. This characteristic was also noted in several other species of rays (Babel, 1967; Snelson et al., 1988; Capapé, 1993; Garayzar et al., 1994; Lasso et al., 1996). The rays flattened body shape causes a reduced abdominal cavity space to accommodate embryos and was considered a possible restrictive fecundity factor (Holden, 1974). Disc width sexual dimorphism with females attaining bigger disc widths might be an attempt to maximize space required for generation of more embryos.

Thorson et al. (1983) estimated that P. motoro attained sexual maturity with a disc width of about 200-250 $\mathrm{mm}$ (males) and 240-320 mm (females), considerably smaller than what has been observed in the present study. This difference might be due to different populations characteristics or to observations made for specimens kept in captivity. Lasso et al. (1996) suggested that male specimens of Paratrygon aiereba matured over $447 \mathrm{~mm}$ of disc width and females over $370 \mathrm{~mm}$. They observed females in reproduction with a total $610 \mathrm{~mm}$ of disc width. Lasso et al. (1996) also observed individuals of $P$. orbignyi maturing with smaller disc width size than those noted in the present study (approximately $230 \mathrm{~mm}$ for males and $295 \mathrm{~mm}$ for females). These differences between previous and present data probably are caused by the fact that the studies were carried out in distinct areas and by the existence of different populations.

Lasso et al. (1996) suggested that males of $P$. motoro and $P$. constellata reached first maturity age when their disc width was half size the maximum disc width observed size but they made no further comments on how long both 
species took to reach these disc width sizes. Until now, Castex (1963b) and Achenbach and Achenbach (1976) were the only ones that estimated the age of first maturity for P. motoro in the wild as being in the latter part of the second year of life, at approximately 20 months, or around three years, respectively. Thorson et al. (1983) suggested that the age of first maturity for P. motoro could be around 4 years of age, however, they observed that in captivity a pair first reproduced at the age of approximately $7 \frac{1}{2}$ years. The great difference in sexual maturity age estimates between Paratrygon aiereba and Potamotrygon sp. C in the present study may be possibly explained by the different growth rate that each of these species probably presents. The "cururu" freshwater stingray is considered a very small species and is also known as "dwarf freshwater stingray". While Paratrygon aiereba is the largest freshwater stingray known to date and adult specimens may easily weigh over $60 \mathrm{~kg}$ (CharvetAlmeida, 2001). Disc width size at sexual maturity for both species (Table 3) also indicates the significant size difference that they present.

When comparing the present results with the ones obtained by other authors some differences are noticed. Different characteristics in the reproductive cycle of species that are present in more than one area or river basin clearly indicate the need for studies in each area where ornamental purpose captures and other activities that might interfere with potamotrygonid reproduction take place. The use of potamotrygonids as ornamental fish requires population management (Araújo, 1998; CharvetAlmeida, 2001) and certainly reproductive aspects must be known and considered when elasmobranch conservation measures are required (Camhi et al., 1998; Musick et al., 2000). It is expected that results obtained until now and new data that is currently being analyzed provide part of the information required to assist decision making in management procedures and help keep the populations of freshwater stingrays on safe grounds.

\section{Acknowledgements}

We acknowledge the partial financial support obtained from ACEPOAM, ACEPOPA, ACEPOAT, CNPq and WWF - Brazil.

\section{References}

ACHENBACH, G. M., and S. V. M. ACHENBACH. 1976. Notas acerca de algunas especies de raya fluvial (Batoidei, Potamotrygonidae) que frecuentan el sistema hidrográfico del Paraná medio en el Departamento La Capital (Santa FeArgentina). Comun. Mus. Prov. Ciencias Nat. Florentino Ameghino, 8: 1-34.

ARAÚJO, M. L. G. 1998. Biologia Reprodutiva e Pesca de Potamotrygon sp. C (Chondrichthyes - Potamotrygonidae), no Médio Rio Negro, Amazonas. Masters Degree Dissertation, Manaus, Instituto Nacional de Pesquisas da Amazônia and Universidade do Amazonas. 171 p.

BABEL, J. S. 1967. Reproduction, life style and ecology of the round stingray, Urolophus halleri. Bull. Calif. Dep. Fish., 137: 1-104.

CAMHI, M., S. FOWLER, J. MUSICK, A. BRÄUTIGAM, and S. FORDHAM. 1998. Sharks and their relatives: ecology and conservation. Switzerland and Cambridge, IUCN/SSC Shark Specialist Group, $39 \mathrm{p}$.

CAPAPÉ, C. 1993. New data on the reproductive biology of the thorny stingray, Dasyatis centroura (Pisces: Dasyatidae) from off the Tunisian coasts. Environ. Biol. Fishes, 38: $73-80$.

CASTEX, M. N. 1963a. Observaciones sobre la raya de río Potamotrygon motoro (Müller y Henle). Comun. Mus. Argent. Cienc. Nat. Bernardino Rivadavia, Hidrobiología, 1(2): 7-14.

1963b. La Raya Fluvial: notas historico-geograficas. Santa Fé, Librería y Editorial Castellví. 119 p.

CASTEX, M. N., and I. MACIEL. 1965. Notas Sobre la Familia Potamotrygonidae Garman 1913. Santa Fé, Dirección General de Recursos Naturales, Publicación Técnica, 14: 1-23.

CHARVET-ALMEIDA, P. 2001. Ocorrência, Biologia e Uso das Raias de Água Doce na Baía de Marajó (Pará, Brasil), com Ênfase na Biologia de Plesiotrygon iwamae (Chondri chthyes: Potamotrygonidae). Masters Degree Dissertation, Belém, Universidade Federal do Pará and Museu Paraense Emílio Goeldi, 213 p.

COMPAGNO, L. J. V., and S. F. COOK. 1995. The exploitation and conservation of freshwater elasmobranchs: status of taxa and prospects for the future. In: The Biology of Freshwater Elasmobranchs. M. I. Oetinger, and G. D. Zorzi (eds.). J. Aquaric. Aqua. Sci., 7: 62-90.

DODD, J. M. 1983. Reproduction in cartilaginous fishes. In: Fish Physiology. W. S. Hoar, D. J. Randall, and E. M. Donaldson (eds.). New York, Academic Press, p. 31-95.

GARAYZAR, C. J. V., C. D. HOFFMANN, E. M. MELÉNDEZ. 1994. Tamaño y reproducción de la raya Dasyatis longus (Pisces: Dasyatidae), en Bahía Almejas, Baja California Sur, México. Rev. Biol. Trop., 42(1): 375-377.

GOULDING, M. 1980. The Fishes and the Forest: explorations in the Amazonian natural history. Berkeley, University of California Press, 280 p.

1997. História Natural dos Rios Amazônicos. Brasília, Sociedade Civil Mamirauá, 208 p.

HOLDEN, M. J. 1974. Problems in the rational exploitation of elasmobranch populations and some suggested solutions. In: Sea Fisheries Research. F. R. Harden-Jones (ed.). New York, John Wiley \& Sons, p. 117-137.

LASSO, C. A., A. B. RIAL, and O. LASSO-ALCALÁ. 1996. Notes on the biology of the freshwater stingrays Paratrygon aiereba (Müller and Henle, 1841) and Potamotrygon orbignyi (Castelnau, 1855) (Chondrichthyes: Potamotrygonidae) in the Venezuelan llanos. Aqua J. Ichthyol. Aquat. Biol., 2(3): 39-52.

LESSA, R. P. T. 1982. Biologie et dynamique des populations de Rhinobatos horkelli (Müller and Müller, 1841) du Plateau 
Continental du Rio Grande do Sul (Brésil). Doctorate Thesis, Université de Bretagne Occidentale, 238 p.

LOVEJOY, N. R. 1996. Systematics of myliobatoid elasmobranchs: with emphasis on the phylogeny and historical biogeography of neotropical freshwater stingrays (Potamotrygonidae: Rajiformes). Zool. J. Linn. Soc., 117: 207-257.

MUSICK, J. A., G. BURGESS, G. M. CAILLET, M. CAMHI, and S. FORDHAM. 2000. Management of sharks and their relatives (Elasmobranchii). Fisheries, 25(3): 9-13.

PERES, M. B., and C. M. VOOREN. 1991. Sexual development, reproductive cycle and fecundity of the school shark Galeorhinus galeus off southern Brazil. Fish. Bull., 89: 655-667.

PRATT, H. L. 1988. Elasmobranch gonad structure: a description and survey. Copeia, 3: 719-729.

PRATT, H. L., and T. OTAKE. 1990. Recommendations for work needed to increase our knowledge of reproduction relative to fishery management. $I n$ : Elasmobranch as Living Resources: advances in biology, ecology and systematics, and the status of fisheries. Pratt, H. L., S. H. Gruber, and T. Taniuchi (eds.). NOAA Tech. Rep. NMFS: 509-510.

ROSA, R. S. 1985. A Systematic Revision of the South American Freshwater Stingrays (Chondrichthyes: Potamotrygonidae). Doctorate Thesis, Williamsburg, College of William and Mary, $523 \mathrm{p}$.

SCHOMBURGK, R. H. 1843. Fishes of British Guiana. In: Naturalist's Library. W. Jardine, (ed.). vol. 40(2). Edinburgh, W. H. Lizars, p. 175-185.
SNELSON, F. F., S. E. WILLIAMS-HOOPER, and T. H. SCHMID. 1988. Reproduction and ecology of the Atlantic stingray Dasyatis sabina, in Florida coastal lagoons. Copeia, 3: 729-739.

TANIUCHI, T., and H. ISHIHARA. 1990. Anatomical comparison of clasper of freshwater stingrays (Dasyatidae and Potamotrygonidae). Jap. J. Ichthyol., 37(1): 10-16.

TESHIMA, K., and K. TAKESHITA. 1992. Reproduction of the freshwater stingray, Potamotrygon magdalenae taken from the Magdalena River System in Colombia, South America. Bull. Seikai Nat. Fish. Res. Inst., 70: 11-27.

THORSON, T. B., J. K. LANGHAMMER, and M. I. OETINGER. 1983. Reproduction and development of the South American freshwater stingrays, Potamotrygon circularis and P. motoro. Environ. Biol. Fishes, 9(1): 3-24.

WINEMILLER, K. 1989. Patterns of variation in life history among South American fishes in seasonal environments. Oecologia, 81: 225-241.

WINEMILLER, K. and D. TAPHORN. 1989. La evolución de las estrategias de vida en los peces de los llanos ocidentales de Venezuela. Biollania, 6: 77-122.

WOURMS, J. P. 1977. Reproduction and development in chondrichthyan fishes. Amer. Zool., 17: 379-410.

1981. Viviparity: the maternal-fetal relationship in fishes. Amer. Zool., 21: 473-515.

WOURMS, J. P., B. D. GROVE, and J. LOMBARDI. 1988. The maternal-embryonic relationship in viviparous fishes. In: Fish Physiology. Hoar, W. S. and D. J. Randall (eds.). San Diego, Acad. Press, p. 1-134. 
